\title{
Article \\ Bottlenose Dolphins Produce Underwater Bubbles Linked to Cognitive Task Engagement but Not Success
}

\author{
Elena Alexander ${ }^{1}$, Mark Abrahams ${ }^{2}$ and Fay E. Clark ${ }^{3, *(\mathbb{D}}$ \\ 1 Faculty of Health Sciences, Bristol Veterinary School, University of Bristol, Bristol BS40 5DU, UK; \\ c119085@alumni.bristol.ac.uk \\ 2 Department of Field Conservation \& Science, Bristol Zoological Society, Bristol BS8 3HA, UK; \\ mabrahams@bristolzoo.org.uk \\ 3 Faculty of Life Sciences, School of Psychological Sciences, University of Bristol, Bristol BS8 1TU, UK \\ * Correspondence: fay.clark@bristol.ac.uk
}

check for updates

Citation: Alexander, E.; Abrahams, M.; Clark, F.E. Bottlenose Dolphins Produce Underwater Bubbles Linked to Cognitive Task Engagement but Not Success. J. Zool. Bot. Gard. 2021, 2 , 287-299. https://doi.org/10.3390/ jzbg2020020

Academic Editor: Lance Miller

Received: 28 April 2021

Accepted: 25 May 2021

Published: 1 June 2021

Publisher's Note: MDPI stays neutral with regard to jurisdictional claims in published maps and institutional affiliations.

Copyright: (c) 2021 by the authors. Licensee MDPI, Basel, Switzerland. This article is an open access article distributed under the terms and conditions of the Creative Commons Attribution (CC BY) license (https:// creativecommons.org/licenses/by/ $4.0 /)$.

\begin{abstract}
Captive mammals respond emotionally toward cognitive challenges, but research has precluded marine mammals. A potential indicator of emotion in toothed cetaceans is a large singular bubble ('burst') emitted from the blowhole, previously linked to surprise and excitement. Our study analysed bursts from a published study on dolphin cognitive enrichment. Bursts were only produced by task-engaged $(72 \%)$ or task-spectating $(28 \%)$ dolphins $(n=6$ males in total). Burst frequency increased with the proportion of task engagement and spectator frequency, but not task progress or success (providing no evidence for an instantaneous 'Eureka moment'). Bursts were reduced in frequency over three weeks, consistent with a decrease in task-engagement. Bursts were significantly more likely to come at the start of a bout of task-engagement than in the middle or end. We suggest bursts were an emotional response signaling dolphins' instantaneous judgement of the task, more likely related to positive affect (interest, curiosity) than negative affect (frustration). They appear unrelated to respiration. It was unclear whether bursts were produced consciously and had a social function. We call for further dedicated research on the emotional valence of cetacean bursts. This will require simultaneous behavioural and acoustic measurements under different levels of more controlled challenge.
\end{abstract}

Keywords: affective state; animal cognition; animal welfare; cetacean; cognitive enrichment; emotion; time-series analysis

\section{Introduction}

The contemporary study of animal cognition increasingly considers the animal welfare implications of cognitive testing in captive settings [1-3]. In addition, cognitively challenging tasks specifically designed to enhance positive welfare or 'affective' states (so-called 'cognitive enrichment' [4,5]), are growing in popularity. However, there are taxonomic and situational biases; emotional responses to cognitive challenges have mostly been studied in farmed and laboratory animals, as well as great apes housed in research centres and zoos.

Exposure to cognitive challenge tasks has been associated with positive mood changes in domestic pigs and goats [6,7]. There is also limited evidence for the instantaneous 'Eureka moment' in domestic cattle and dogs, which showed signs of positive excitement shortly after a novel task was solved [8,9]. However, cognitive challenge is not always a positive situation for animals. In great apes, exaggerated self-scratching (a validated indicator of anxiety, see [10]) and task-directed aggression were associated with increased task complexity and failure to task-solve [3,11-13]. Collectively, these studies point towards mixed emotional valence of cognitive challenge in nonhuman mammals, using behaviour as a proxy for emotion $[14,15]$. 
The affective (emotional) responses of non-terrestrial mammals to cognitive challenge lacks study. There is a particular irony for cetaceans; their cognition has been studied intensively in captive settings, but is seldom applied to their captive care [16]. The production of underwater bubbles by cetaceans is an interesting phenomenon which may provide insight. Cetaceans produce underwater bubbles as they release air from their blowholes. This air comes from the lungs and can thus be seen as a form of exhalation, although true respiration must happen above the surface to breathe in air [17]. A comprehensive review of cetacean bubble production [18] showed that most reports come from captive studies and lack consistent terminology. The specialized bubble-nets produced by humpback whales Megaptera novaeangliae for foraging (e.g., [19]) will not be considered further, and we refer hereon to small, captive dolphin species.

The link between cetacean bubble production and affective state requires further study. Most reports of bubble production in captive cetaceans are in contexts of high arousal [18] suggesting bubbles are linked to internal state, but the valence (relative positive/negative nature) is unclear. Bubble rings, defined by as "a release of air that forms a single, unbroken torus" ([18], p. 118) have been associated with positive affective state, because they are sometimes 'played' with after production [20,21]; however, they are also produced in negative contexts [18]. Interestingly, captive cetaceans can be trained to produce bubble rings, showing that this bubble type can be under conscious control. It has not been reported whether other bubble types can be trained.

A bubble of particular interest is the 'bubble burst' (from hereon called a burst). This type of bubble is broadly defined as "the sudden release of a large amount of air resulting in a cloud-like clustering of bubbles" ([18], p.113). The authors [18] also recorded a rarer subtype: a large, singular bubble (we expand on this by describing its shape as a mushroom cloud). The function of bursts is debated in the limited literature available; most reports suggest that bursts are produced in response to social threat or aggression $[18,22,23]$ or surprising positive or negative stimuli [24-26]. The singular burst form was witnessed by Clark et al. [27] in a study of captive bottlenose dolphin Tursiops truncatus cognitive enrichment. The authors did not explore the potential function of bursts (which they called spherical bubbles), but suggested they may be a " . . visual expression of excitement ... serving as a large visual signal to conspecifics" ([27], p. 617). One of the authors proposed that the bursts were 'aha bubbles' (Kuczaj, pers. comm), signaling the "Eureka moment of problem-solving" (sensu [8]). Similarly, bursts have been referred to as 'query balloon(s)' ([24], p. 540), linked to interest and surprise.

The aim of the current study was to use the Clark et al. (2013) [27] dataset to evaluate the potential function of bursts in relation to a dolphin's exposure to an underwater task (i.e., a cognitive challenge). We hypothesized two functions of bursts: (1) an emotional response to cognitive challenge (indicating either positive or negative affective state), and (2) a respiratory function. We reasoned that a dolphin may express its appraisal of the challenge through bubble production, and this may or may not be conscious. We also reasoned that expelling air from the blowhole may allow a dolphin to spend a greater period of time underwater using the task, or signify changes related to changes in activity level (i.e., a sign of physical exertion). A third hypothesized function of bursts, that they were a communicative signal during task engagement (i.e., to attract other dolphins in the group), could not be tested with the current data due to the study design (free group access to the device). The Clark et al. [27] dataset provided an opportunity to examine continuous behavioural responses to a cognitive challenge in a group setting in an understudied species.

\section{Materials and Methods}

\subsection{Study Site and Subjects}

Full details of the original study are provided in the original article by Clark et al. [27]. In summary, the study took place at Six Flags Discovery Kingdom, California between April and May 2012. Subjects were a bachelor group of six Atlantic bottlenose dolphins 
aged between 10-26 years, and the original paper [27] details social dynamics and group tenures. Dolphins were housed in two interconnected saltwater pools (578,000 gallons). Trials took place in a rectangular pool (162,000 gallons, $4 \mathrm{~m}$ depth) which had underwater viewing windows. Data were collected when the facility was closed to the public, MondayWednesday each week between 13:30 and 15:30 h.

\subsection{Task Design and Set-Up}

The underwater task was a novel design and construction by Clark et al. [27]. In summary, it was a symmetrical, pyramid-shaped arrangement of white PVC pipes (Figure 1). A 750-mm wide opening was cut into the front of all the pipes, so that dolphins could see and physically manoeuvre a $90-\mathrm{mm}$ diameter rubber ball (Kong ${ }^{\circledR}$, Golden, CO, USA) through the pipes. Dolphins could use their rostrums to move the ball from the top of the task to the bottom, where it fell inside an exit pipe. Alternatively, they could move the task itself to move the ball (or a tail-beating action which moved the ball without physical contact).

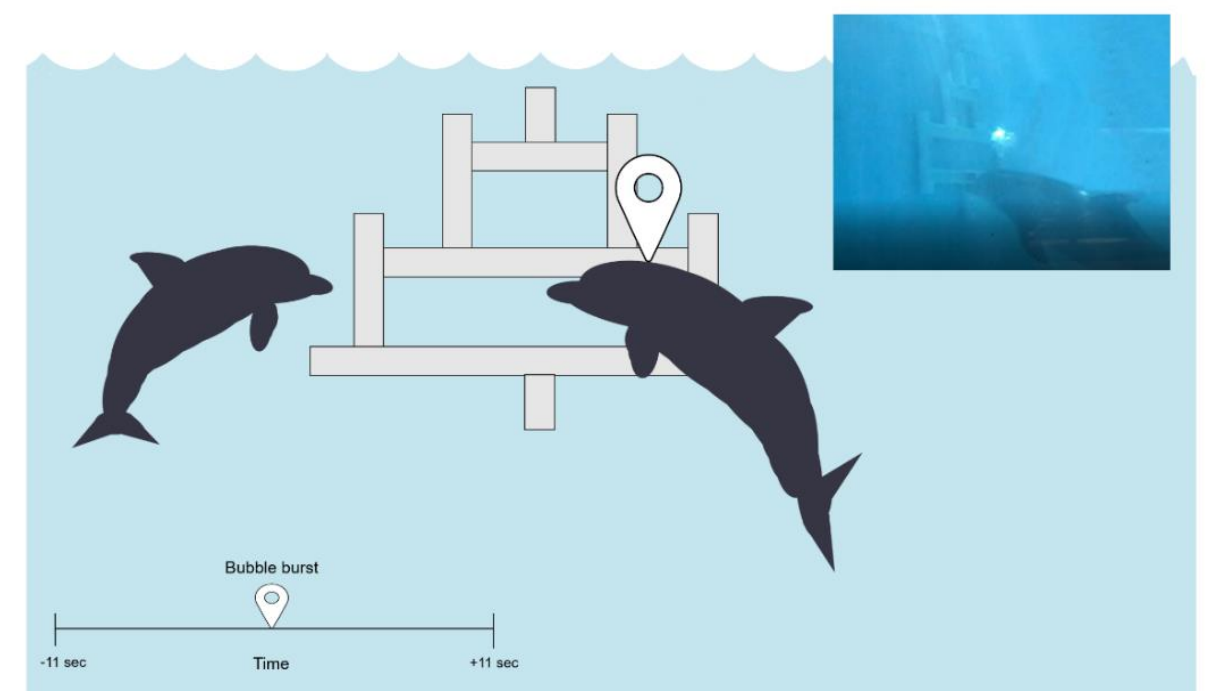

Figure 1. A bottlenose dolphin engaged with the underwater task, and another dolphin spectating within one body length (approximately $2.5 \mathrm{~m}$ ). Behaviour sequences within $11 \mathrm{~s}$ of a burst were analysed using THEME, and sequences $11 \mathrm{~s}$ duration were analysed using a GLM. Photograph (inset) shows real footage from underwater window.

The task was presented with rubber balls inside the pipes over a two-week period (one week after the baseline period). The task was presented over three consecutive days, followed by a four-day gap, then presented for another three days. At the beginning of a trial, the task was submerged in the test pool $30 \mathrm{~cm}$ below the surface of the water. The task was tethered using an abseiling rope so that the dolphins could manoeuvre it, but it could not drift more than $0.5 \mathrm{~m}$ from the pool wall. During a trial, the task was submerged in the pool for $30 \mathrm{~min}$ (called a half-trial), then completely removed for $15 \mathrm{~min}$, then resubmerged for a final $30 \mathrm{~min}$. Each time the task was solved (a ball entered the exit pipe), an experimenter added another ball to the entry pipe. A short extension took place after six rubber ball trials: the task was provided for an additional two days with gelatine balls inside. Due to time constraints, the experimenters only ran one 30-min gelatine half-trial each day. Gelatine balls had the same diameter as rubber balls, but the exit pipe was left open and they were safe for the dolphins to play with. Over the course of the study, the task was only installed in the pool during task trials, and no feeding or human interaction took place during those times. 


\subsection{Behavioural Data}

\subsubsection{Baseline}

Each dolphin was recorded in Clark et al.'s study [27] as a focal individual for a total of $60 \mathrm{~min}$. Each dolphin was observed $10 \mathrm{~min}$ per day for six days (Monday-Wednesday) and the order of focal subjects was randomised without replacement. Observations were made by one observer on foot, from above and below the water, across both interconnected pools. State behaviour was sampled at 1-min intervals, and social interactions were recorded by all-occurrence sampling [28]. Because no bursts were observed in the baseline, no analysis of baseline behaviour was performed in the current study.

\subsubsection{Task Trials}

The test pool was filmed through an underwater window using a tripod-mounted video camera (Panasonic SDR-H40, Panasonic Corp., Osaka, Japan). Video data were coded by one observer using continuous sampling for every dolphin within one body length (approximately $2.5 \mathrm{~m}$ ) of the task (Figure 1). This included latencies, durations and frequencies of task engagement (Table 1), successes (extraction of balls), and all associated social interactions. Clark et al. [27] defined a bout of task-engagement as continuous task engagement, which may include a break of up to $3 \mathrm{~s}$ to take a breath. Breaks of longer than $3 \mathrm{~s}$ were considered to be a cut-off between different bouts.

Table 1. Ethogram for captive male dolphins in response to an underwater cognitive task.

\begin{tabular}{|c|c|}
\hline Behaviour & Description $^{1}$ \\
\hline \multicolumn{2}{|l|}{ Bubble production: } \\
\hline Bubble burst & $\begin{array}{c}\text { A large singular bubble, shaped like a mushroom cloud, } \\
\text { produced from the blowhole. }\end{array}$ \\
\hline Bubble scrap & $\begin{array}{c}\text { A thin ribbon-like bubble, produced from the blowhole, which is } \\
\text { immediately eaten by the producer. }\end{array}$ \\
\hline \multicolumn{2}{|l|}{ Task engagement: } \\
\hline Approach & $\begin{array}{l}\text { Movement within one body length (approx. } 2.5 \mathrm{~m} \text { ) of the task, } \\
\text { with the body aligned towards the task (i.e., not passively } \\
\text { swimming past). }\end{array}$ \\
\hline Observe & $\begin{array}{l}\text { Stationary or slowly moving within one body length of the task } \\
\text { while paying close visual attention to the task. Head may be } \\
\text { moving around. }\end{array}$ \\
\hline Contact & $\begin{array}{l}\text { Physical contact with the task. Includes push, pull, bite, slide ball } \\
\text { (with rostrum), gentle touch. }\end{array}$ \\
\hline Play with ball & $\begin{array}{l}\text { Playful interactions with the (gelatine) task ball. Includes } \\
\text { throwing ball around in water, mouthing, chasing and tussling. }\end{array}$ \\
\hline \multicolumn{2}{|l|}{ Task spectating: } \\
\hline Vigilance of task user & $\begin{array}{c}\text { Close visual inspection of a dolphin engaged with the task, } \\
\text { within one body length. }\end{array}$ \\
\hline Vigilance of experimenter & Close visual attention to experimenters or trainers above water. \\
\hline \multicolumn{2}{|l|}{$\begin{array}{l}\text { Possible frustration } \\
\text { behaviour: }\end{array}$} \\
\hline Jaw-clap & Rapid opening and closing of the jaw. \\
\hline Tail-beat & Strong vertical movement of the tail flukes. \\
\hline
\end{tabular}




\subsection{Statistical Analyses}

\subsubsection{Initial Analyses}

We performed a Kruskal-Wallis test followed by post hoc Dunn multiple comparisons with corrected $p$ values to find if there was a significant difference in burst production between individual dolphins. All analyses except THEME analysis, Generalised Linear modeling, and the Wald-Wolfowitz runs test were performed in GraphPad Prism (version 9.1.0, GraphPad Software, San Diego, CA, USA).

\subsubsection{THEME Analysis of Behavioural Sequences}

We used the software programme THEME (v.6; Noldus Technologies, Wageningen, Netherlands) to explore whether bursts were temporally linked to the performance of any other behaviours. If two behaviours are linked within a certain time interval more often than expected by chance, THEME defines them as a 'T-pattern' [30,31]. THEME then randomises the original dataset (through Monte Carlo simulation) and compares the number of T-patterns in the original and randomised datasets to ascertain which T-patterns occur more often than expected by chance.

Behavioural sequence data from all individuals and trials were first merged into a single concatenated, time-stamped dataset (T-data). This was done so that the continuous order of each burst could be retained regardless of which dolphin produced or responded to it. We were only interested in T-patterns containing bursts. Therefore, we identified each burst in the T-data and trimmed sequences to a total length of $22 \mathrm{~s}: 11 \mathrm{~s}$ before and $11 \mathrm{~s}$ after a burst (Figure 1). This sequence length was chosen because it took approximately $11 \mathrm{~s}$ to swim the longest length of the pool based on an average swim speed of $1.77 \mathrm{~m} / \mathrm{s}[32,33]$. T-patterns were only accepted as significant if THEME detected them at least 3 times in our T-data, and then through Monte Carlo simulation (5 rotation and 5 shuffling events, level of significance $p$ <.005). THEME recursively searches for T-patterns, meaning that once a T-pattern is found at level 1 (burst linked to one other behaviour a), it then searches at level 2 ((burst, (a), (b), and so on. Note that THEME has a setting to look for 'bursts' of a certain behavior or pattern occurring repetitively over time. The software's use of this term is not related to how we use it as a type of cetacean bubble.

\subsubsection{Generalised Linear Modelling Task Engagement and Spectating}

To identify whether burst production was associated with task engagement and/or task-spectating, we performed a binomial Generalized Linear Mixed-Effects Model (GLMM) and Generalized Linear Model (GLM) in R (software version 1.3.959 with the associated lme4 package). For each 30-min half trial, we segmented the data into sequences of 11-s duration, so that they had continuity with THEME analysis. Within each 11-s sequence, we recorded the following: (i) Burst production was scored as binary $(1=$ at least one burst present, $0=$ bursts absent); (ii) The proportion of the interval spent: task-engaged (observe, contact, success) and signs indicative of frustration (jaw-clap, tail-beat); (iii) The total frequency of spectators present within 1 body length, task successes, and new balls loaded into the task; (iv) Ball position changes within the task were scored as binary ( $1=$ at least one change in position within the maze pipes, $0=$ no change in position). We treated burst production as the response variable and the other variables as explanatory. Both 'success' and 'new ball' were included as variables because, although each success was followed by a new ball, there was a variable time delay between these events.

We tested for multicollinearity between explanatory variables using Variance Inflation Factor, which revealed low multicollinearity (below 1.5 in all cases). We used the 'scale' function to centre and scale explanatory variables to improve model convergence and comparison of effect sizes. We initially created a GLMM, specifying the half-trial as a random effect to account for data-nesting. Our model failed to converge; hence, we simplified to a GLM by removing the random effect. To avoid overestimating the effect size of significant predictors, we did not undertake a model simplification procedure, but instead, reported a global model. We compared our null to our global GLM using 
a chi square test, which, alongside lower Akaike Information Criteria values, supported our global model. We plotted our model residuals to visually assess our GLM; residuals were non-normal.

To consider the placement of bursts within bouts of task-engagement, we compared the frequency of bursts occurring in the beginning, middle, and end third of bouts, using a Chi Square Goodness of Fit test.

\subsubsection{Burst Production as a Function of Respiration}

Clark et al. [27] allowed up to $3 \mathrm{~s}$ for surface breathing within a bout of task engagement without coding respiration as a separate event. Therefore, to substitute for confirmed respiration data, we investigated the regularity of burst production in one dolphin (Brandy, who was the most task-engaged subject and also the highest burst producer) to elucidate whether bursts could be regular expiration events. Intervals between Brandy's bursts were calculated within each 30-min half trial, excluding single bursts where necessary at the start and end. Burst intervals were compared to a published average respiration rate of captive bottlenose dolphins (median 2.0 breaths per $\min , n=9$ dolphins; [34] using a one-sample Wilcoxon signed rank test. Additionally, we conducted a non-parametric Wald-Wolfowitz runs test in $\mathrm{R}$ to identify whether bursts occurred at random intervals.

\section{Results}

A total 106 bursts were observed over the course of the study, all within one body length of the task. None were produced during baseline observations. All dolphins produced bursts (Table 2, Figure 2) and there was an overall effect of individual on burst frequency $(H=20.19, p<0.005)$. Post hoc Dunn multiple comparisons showed significant differences between the highest burst producer and the two lowest burst producers: Brandy versus Ty $(Z=3.723, p<0.01)$ and Brandy versus Cupid $(Z=4.000, p<0.001)$. As for other bubble types (see Table 1 for definitions), dolphins produced 21 'bubble scraps' over the course of the study. Correcting for differences in observation length (baseline was a total $6 \mathrm{~h}$, trials were a total $7 \mathrm{~h}$ ), the baseline rate was 0.5 scraps $/ 30 \mathrm{~min}$ and the trial rate was 1.9 scraps $/ 30 \mathrm{~min}$. No bubble rings were observed during baseline or trials, but all dolphins could blow bubble rings on command as part of a suite of trained behaviours (D. Cameron, pers comm).

Table 2. Summary of burst production and task engagement by six male bottlenose dolphins.

\begin{tabular}{|c|c|c|c|c|c|c|}
\hline $\begin{array}{c}\text { Subject } \\
\text { (Age in Years) }\end{array}$ & $\begin{array}{l}\text { Rearing } \\
\text { History }\end{array}$ & $\begin{array}{c}\text { Burst } \\
\text { Frequency }\end{array}$ & $\begin{array}{c}\text { Success } \\
\text { Frequency }\end{array}$ & $\begin{array}{c}\text { Total Task } \\
\text { Engagement (min) }\end{array}$ & $\begin{array}{l}\text { Total Bout } \\
\text { Frequency }\end{array}$ & $\begin{array}{c}\text { Median Bout } \\
\text { Duration (s) }\end{array}$ \\
\hline $\begin{array}{l}\text { Brandy } \\
\text { (12) }\end{array}$ & c & 47 & 12 & 134 & 205 & $26(40)$ \\
\hline $\begin{array}{l}\text { Brisby } \\
(18)\end{array}$ & c & 17 & 5 & 92 & 141 & $26(37)$ \\
\hline $\begin{array}{l}\text { Sonny } \\
(12)\end{array}$ & c & 17 & 0 & 51 & 93 & $21.5(41.8)$ \\
\hline $\begin{array}{l}\text { Merlin } \\
(26)\end{array}$ & $w$ & 12 & 0 & 20 & 43 & $22(26.5)$ \\
\hline $\begin{array}{l}\text { Ty } \\
(22)\end{array}$ & c & 7 & 0 & 36 & 91 & $18(21.5)$ \\
\hline $\begin{array}{l}\text { Cupid } \\
(10)\end{array}$ & $\mathrm{w}$ & 6 & 0 & 27 & 65 & $16(35)$ \\
\hline Total & & 106 & 17 & 360 & 638 & \\
\hline
\end{tabular}

Subjects are arranged in order of decreasing burst frequency. $\mathrm{c}=$ captive born, $\mathrm{w}=$ wild born and rescued. Merlin, the oldest dolphin, was dominant. Cupid was sub-adult. The interquartile range of the median is shown in brackets. 


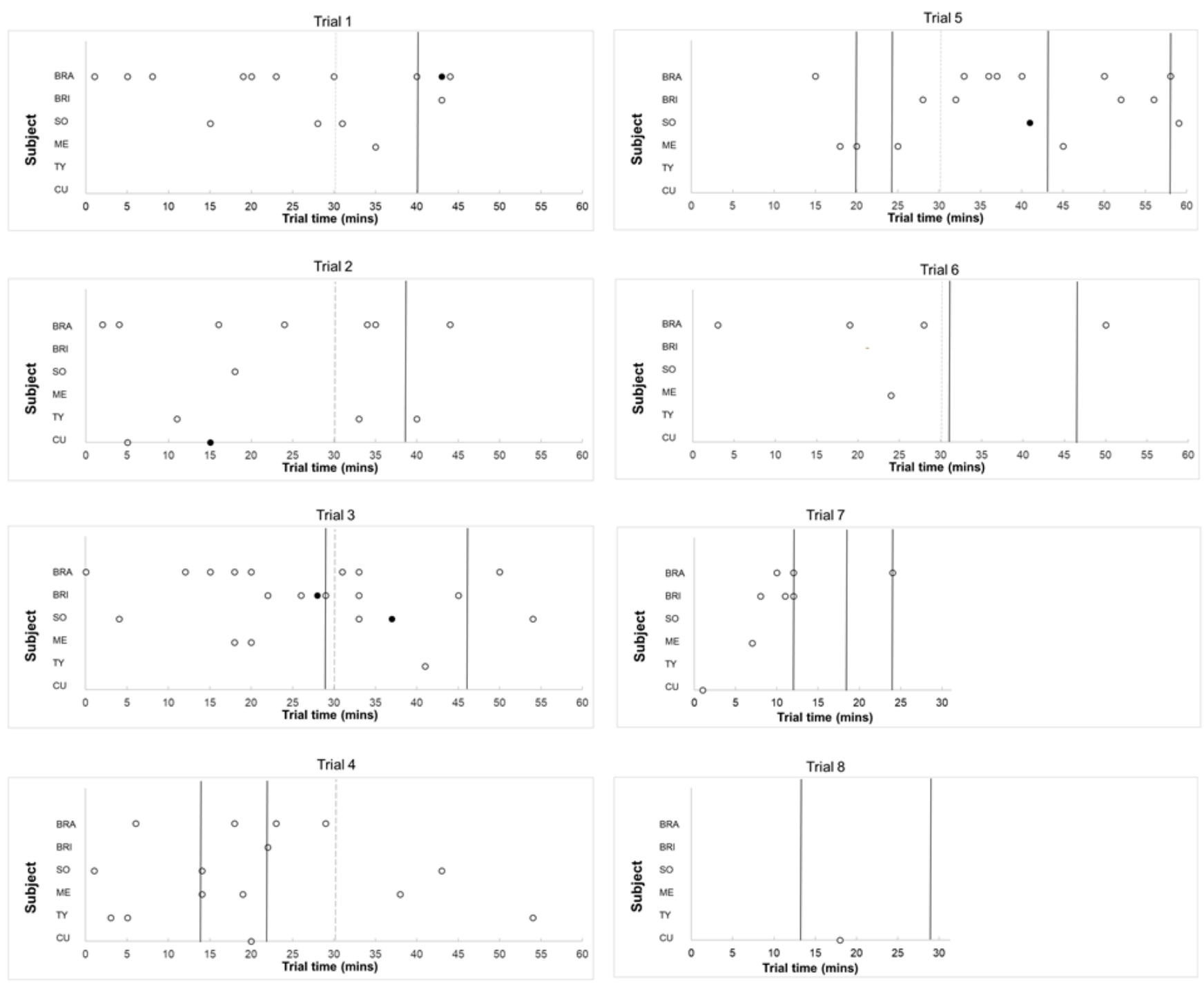

Figure 2. Occurrence of 106 underwater bubble bursts (open circle $=1$ burst, closed circle $=2$ bursts) and task successes (vertical solid lines) by dolphins over eight trails. Dolphin names are abbreviated to their first $2-3$ letters. Bursts and successes are plotted within 1-min intervals. Trials 1-6 (rubber task ball) consisted of two 30-min half-trials, separated by a 15-min break (vertical dashed line). Trials 7-8 (gelatine task ball) consisted of one 30-min half-trial each.

The total burst frequency that we report is greater than the value reported by Clark et al. [27], because they only reported bursts in the first trial condition of their study (rubber ball, 12 half-trials, $n=94$ bursts) and omitted bursts in the shorter, second trial condition (gelatine ball, 2 half-trials trials, $n=9$ bursts). We identified a further occurrence of 3 bursts in the rubber ball condition which had previously been coded as an unknown bubble type, but they fit the description of bursts. The frequency of bursts decreased slightly over time, which is also a decrease between the two conditions. The median (plus interquartile range IQR) burst rates were as follows. Rubber ball condition: median 8 bursts/half-trial (IQR 5.8), gelatine ball condition: median 5 bursts/half-trial (IQR 3.5).

THEME analysed 105 behaviour sequences of 22-s duration containing a burst at $11 \mathrm{~s}$ and at least one other behaviour within $11 \mathrm{~s}$. One burst (Brandy, burst 15 in trial 2) was excluded because no other behaviours occurred within $11 \mathrm{~s}$ of the burst. A total of 15 different behaviours were found to occur within $11 \mathrm{~s}$ of a burst; $13 / 15$ were task engagement behaviours (observe task; contact task: touch, slide, push, pull, bite; success; retrieve ball; play with ball); bubble production (another burst, scrap bubble, unidentified); and tail-beat. Moreover, 2/15 behaviours were spectating (watching a task-engaged dolphin 
or the experimenter). Five behaviours which did not occur within $11 \mathrm{~s}$ of a burst were: approach, new ball load, task submerge (at the start of a half-trial), task removal (at the end of a half trial), and jaw-clap.

A total of 413 T-patterns were detected by THEME, and 364 of these contained bursts $(88 \%)$. Only 4 different behaviours were found in T-patterns with bursts. These were all task-engagement behaviours: observing, touching, pushing, and biting. We found that T-patterns including observing and pushing behaviours (i.e., level 2 T-patterns) were most common (56\%), while T-patterns including only observing or pushing (i.e., level 1 T-patterns) were the second and third most commonly detected ( $18 \%$ and $17 \%$ respectively).

Only two dolphins solved the task; these dolphins also had the highest levels of task engagement (Table 1). When considering burst frequency, $72 \%$ bursts were produced by task-engaged individuals, and the remaining $28 \%$ were performed by task spectators. When considering the proportion of time spent task-engaged or spectating, the GLM revealed that the proportion of time spent task-engaged was a significant positive predictor of burst presence within the same interval $(p<0.001$, Table 3). The GLM also revealed that the frequency of spectators present within an 11-s interval was a significant positive predictor of bubble production within that same interval $(p<0.001)$. The frequency of successes, new ball loads, and ball location changes within an interval were not significant predictors of burst presence within the same interval. Only 10 bursts (9\%) occurred within 1 min of a success, further supporting no link between task success and burst production (Figure 2).

Table 3. GLM model summary.

\begin{tabular}{cccc}
\hline Explanatory Variable & Regression Coefficient & Standard Error & $p$-Value \\
\hline $\begin{array}{c}\text { Proportion of interval }^{1} \text { spent } \\
\text { task-engaged }\end{array}$ & 0.66 & 0.16 & $<0.001$ \\
\hline Frequency spectators & 0.54 & 0.09 & $<0.001$ \\
\hline Frequency successes & 0.13 & 0.07 & 0.061 \\
\hline Frequency new ball loads & -0.51 & 17.51 & 0.977 \\
\hline Frequency ball location changes & -0.11 & 0.10 & 0.254 \\
\hline${ }^{1}$ Interval refers to 11-s intervals within a 30-min half trial & &
\end{tabular}

Two frustration-related behaviours (jaw-claps and tail-beats, see Table 1) were not observed during baseline and were rarely observed during task trials. Jaw-claps were produced once each by Brandy and Brisby during trial 1. Brandy performed ten tail-beats with decreasing frequency throughout the trials, and Brisby performed only one tail-beat.

For the bursts occurring during task-engagement ( $n=76$ bursts), there was a difference in the timing of these bursts. Most bursts occurred at the beginning of a bout $(69 \%)$, which was significantly higher $\left(\mathrm{X}^{2}(\mathrm{df}=2, n=106)=59.152, p<0.001\right)$ than the middle $(17 \%)$, and end (14\%). Figure 3 is a violin plot showing the timing of bursts as a proportion of the duration of task-engagement. The relatively wider base reflects that more bursts occurred at the beginning of bouts (closer to 0 ) than the middle or end (closer to 1 ).

With regards to respiration, 35 inter-burst intervals were calculated for the highest burst producer (Brandy). The median inter-burst interval was $330.4 \mathrm{~s}$ with an IQR of $436 \mathrm{~s}$. This converted to a median of 0.33 bursts per minute (IQR $0.37 \mathrm{~s}$ ). When compared to a median respiration rate calculated for captive bottlenose dolphins (2.0 breaths per minute, [34]), Brandy's burst rate was significantly lower than the respiration rate $(Z=-1.692, p<0.0001)$. Bursts also occurred at random intervals $(Z=-0.35, n=17$ runs, $p>0.05)$. Visual inspection of Figure 2 further indicated that bursts were randomly spaced across half-trials rather than occurring at regular intervals. 


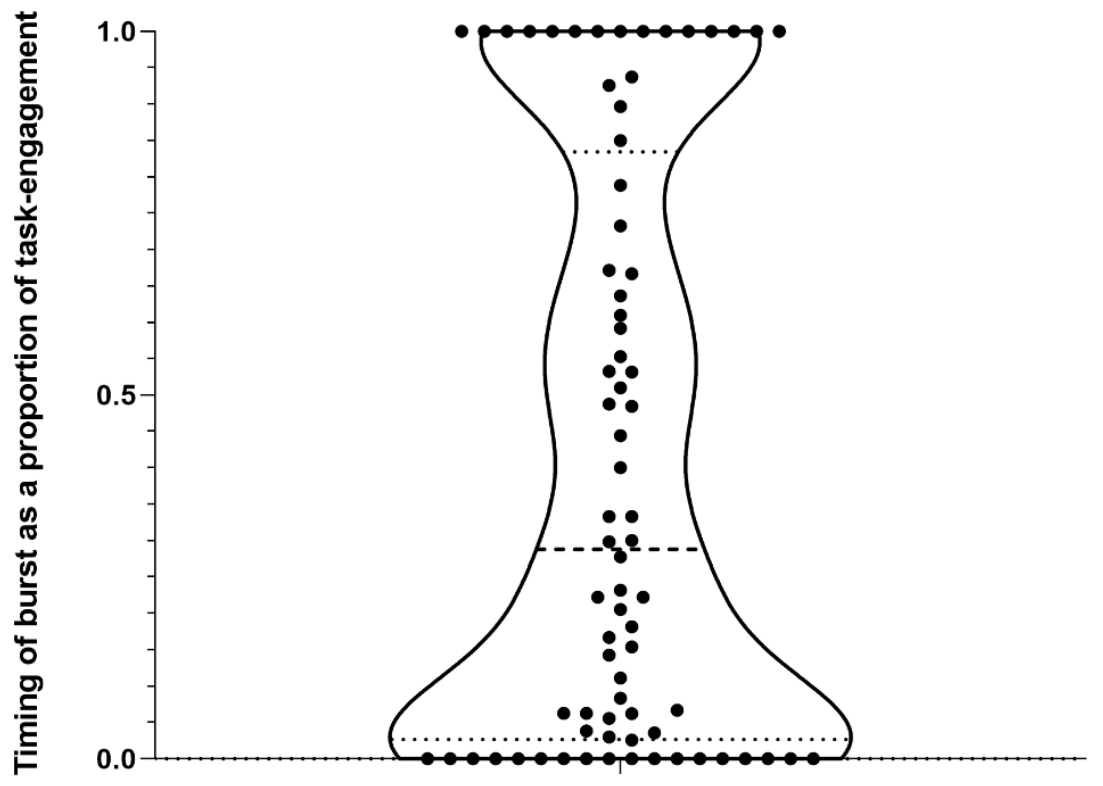

Figure 3. Timing of bursts ( $n=76$ closed circles) within bouts of task-engagement. The timing of each burst is shown as a proportion of the duration of the bout it occurred within. Dashed line: median, dotted lines: quartiles.

\section{Discussion}

\subsection{Burst Production, Task Engagement, and Affective state}

Only task-engaged or spectating dolphins produced bursts; this is supported by previous findings that bursts are produced by captive toothed cetaceans in times of high arousal [18]. Increased task engagement (particularly observing, touching, pushing, and biting the task) was positively associated with burst production within our chosen time interval (11 s). When we plotted the temporal positions of bursts followed by confirmatory analysis, we found that bursts significantly most often occurred at the beginning of bouts of task engagement. The task was placed into the pool on 14 occasions and despite a trend towards decreased burst production over time (the common phenomenon of habituation [35]), bursts occurred across trials rather than at the beginning and end (which would signify excitement/surprise at the task of leaving and entering the water). In the future, we recommend also examining burst production in response to novel objects and other enrichment tasks, for comparison.

We suggest that bursts could be an emotional response to dolphins' early judgement of the cognitive challenge as a spectator or a user. By 'early', we mean that bursts seemed to occur before or early during task engagement, as opposed to after task engagement. This fits with appraisal models of emotion which state that animals make an initial judgement of events which manifest as an emotional response [36,37]. It also fits with several other authors' opinions that bursts are startle responses [23], or signs of increased interest/curiosity [24,26,38,39]. As stated by [26], brief reactions of surprise can be positive for captive animals and we would also not categorize 'surprise' towards the task as negative. We suggest that bursts indicate a positive affective state (i.e., interest, curiosity) rather than a negative affective state.

In contrast to previous reports of bursts, we did not find an association with negative arousal [40-43]). Task engagement was voluntary and the task contained no food reward; therefore, we assume all task-use was highly motivated. Only $6 \%$ of bursts were made within $11 \mathrm{~s}$ of swimming away from the task (i.e., ending a bout). There was no link between bursts and behavioural indicators of frustration. Tail-beating, a possible indicator of frustration, was not significantly associated with burst production, and Clark et al. [27] suggested that tail-beating was a problem-solving strategy to move the ball in the pipes. In order to investigate the valence of emotional responses further, we must look at the effect 
of different types of cognitive challenge tasks on burst production (and other behavioural indicators). We also believe that there is value in exploring whether a burst can be trained, i.e., whether it can be placed under conscious control in the same way as bubble rings.

Our study found no evidence of the Eureka moment; in other words, no evidence that a burst was a dolphin's emotional response to solving the task (or making significant progress). Less than $10 \%$ of bursts occurred within 1 min of solving the task. However, we issue a word of caution related to task design. Clark et al.'s [27] task did not have a clear solution when compared to other cognitive tasks for terrestrial mammals, such as opening a gate or food container to access food [8,9]. Despite decades of cognitive research, we still have much to learn about dolphins' perceptions of physical maze tasks, and dispute whether the solution to the task as designed by Clark et al. [27] was in fact 'understood' by dolphins. For future research, we suggest that a less ambiguous task design with a clear pass / fail modality may aid in measuring animal responses to their own success. Connected to this is the production of 'victory squeals' performed by dolphins at the moment of fish capture, at a trainer's bridge (secondary reinforcement before a fish reward), and when solving physical problem-solving tasks $[44,45]$. The authors $[44,45]$ suggest that the squeal vocalization is an indicator of emotion and its connection to the bridge reinforcer suggests a positive anticipation of the fish reward. Unfortunately, Clark et al. [27] did not collect acoustic data during trials (i.e., using a hydrophone) and therefore, we do not know if bursts were associated with sound production. The collection of such data is crucial in the future.

\subsection{Does Burst Production Have a Social Function?}

Clark et al. [27] suggested that bursts were a visual signal to conspecifics, but we could not find a clear evidence to support this hypothesis. The total number of spectators present was a significant positive predictor of burst production. However, as discussed previously, this type of analysis did not identify a cause-effect relationship. Bursts could be a social recruitment signal (i.e., to call other dolphins over to the task, see [46] for recent research on dolphin vocalisations during collaboration) or an unintentional display which still caught the attention of conspecifics. Due to a small pool size, this could not be tested confidently with the current dataset. As reported in the original study by Clark et al. [27], task-use was primarily a lone activity. Because the task did not require a social partner (in contrast to specifically designed dolphin collaboration tasks, ref. [47-49]), it seems unlikely that a burst was a 'call for help', but it would be interesting to contrast bursts produced during different types of task, i.e., lone and social. In the future, we recommend examining whether the number of spectators clearly increases shortly following a burst. This requires a pool size large enough to allow dolphins to choose and maintain/reduce their spatial positions relative to each other [50]. The main unanswered question is whether bursts are associated with dolphin vocalization. We do not know if bursts were associated with sound production because, unfortunately, Clark et al. [27] did not collect such data. Some cetacean vocalisations such as whistles and moans have been associated with bubble production, while others have not $[24,42,51,52]$.

\subsection{Does Burst Production Have a Respiratory Function?}

Inter-burst intervals calculated for one dolphin, Brandy, were randomly spaced and were not statistically similar to a captive dolphin's natural respiration rate $(2.2 \mathrm{breaths} / \mathrm{min}$, ref. [34]), which further supports that bursts were not regular respiration events. Given the task's close proximity to the water surface (depth $30 \mathrm{~cm}$ ), dolphins were not placed under any discernible diving pressures and it was not difficult for them to rise to breathe during task engagement (in fact, Clark et al. [27] did not score departures of up to $3 \mathrm{~s}$ to breathe when recording bouts). We propose one alternate hypothesis (although we do not find it very plausible given the lack of diving pressure in the current study). Because bursts mainly occurred at the beginning of task engagement, this might indicate that they were conscious expirations allowing a dolphin to spend more time underwater engaging with 
or spectating the task. If so, bursts could be interpreted as a type of anticipatory event behaviour; a dolphin is releasing excess air in preparation for spending time underwater with the task. If this is the case (and would require further study to confirm, including confirmation of conscious control over bursts by training this behaviour with operant conditioning), burst production could be used by researchers as an indicator of positive anticipation [53]. Further data will be needed to measure bursts in association with surface breathing, and potentially placing a task at different depths to challenge respiratory limits.

\section{Conclusions}

Taking all results into consideration, we cautiously suggest that bursts are an indicator of (positive) surprise or excitement towards a cognitive challenge. However, we cannot rule out an alternative function; bursts may allow a dolphin to release excess air to remain underwater for longer and, therefore, bursts indicate anticipation of future task engagement. These functions may not necessarily be mutually exclusive, and bursts may serve dual functions. In either case, our study implicates bursts in cognitive engagement; our conclusion is that bursts are associated with voluntary task-engagement, but do not reflect task changes such as ball loads, location changes, or successes. It is interesting and perhaps somewhat disappointing that challenge progress and success were not linked to bursts. However, the original study by Clark et al. [27] was not designed to directly assess the function of bursts and our study points to where new methods are required, including changes to task design. Further research is important to study the link between bursts and cetacean affective state; this will help to evaluate the welfare impacts of cognitive tasks on cetaceans and to evaluate new designs of cognitive enrichment.

Author Contributions: Conceptualization, E.A. and F.E.C.; all authors contributed equally to methodology and data curation. Analysis, E.A. and M.A.; writing-original draft preparation, E.A.; writingreview and editing, E.A. and F.E.C.; visualization, F.E.C. All authors have read and agreed to the published version of the manuscript.

Funding: This research received no external funding.

Institutional Review Board Statement: The study was approved by the University of Bristol Animal Welfare and Ethical Review Body (AWERB) reference UIN UB/20/17 in June 2020.

Informed Consent Statement: Not applicable.

Data Availability Statement: The data are available upon request.

Acknowledgments: We wish to acknowledge the late Stan Kuczaj, University of Southern Mississippi who inspired this study by suggesting a potential function of bubble bursts. Thanks go to Stephanie King, University of Bristol for providing help and advice concerning behavioural analyses. Thanks also go to three anonymous peer reviewers for their very insightful comments. At the time of writing, F.E.C. held a visiting research associate position at the University of Bristol.

Conflicts of Interest: The authors declare no conflict of interest.

\section{References}

1. Herrelko, E.S.; Vick, S.J.; Buchanan-Smith, H.M. Cognitive research in zoo-housed chimpanzees: Influence of personality and impact on welfare. Am. J. Primatol. 2012, 74, 828-840. [PubMed]

2. Whitehouse, J.; Micheletta, J.; Powell, L.E.; Bordier, C.; Waller, B.M. The impact of cognitive testing on the welfare of group housed primates. PLOS ONE 2013, 8, e78308.

3. Wagner, K.E.; Hopper, L.M.; Ross, S.R. Asymmetries in the production of self-directed behavior by chimpanzees and gorillas during a computerized cognitive test. Anim. Cogn. 2016, 19, 343-350.

4. Clark, F.E. Great ape cognition and captive care: Can cognitive challenges enhance well-being? Appl. Anim. Behav. Sci. 2011, 135, $1-12$.

5. Clark, F.E. Cognitive enrichment and welfare: Current approaches and future directions. Anim. Behav. Cogn. 2017, 4, 52-71. [CrossRef]

6. Zebunke, M.; Puppe, B.; Langbein, J. Effects of cognitive enrichment on behavioural and physiological reactions of pigs. Physiol. Behav. 2013, 118, 70-79. [CrossRef] [PubMed] 
7. Oesterwind, S.; Nürnberg, G.; Puppe, B.; Langbein, J. Impact of structural and cognitive enrichment on the learning performance, behavior and physiology of dwarf goats (Capra aegagrus hircus). Appl. Anim. Behav. Sci. 2016, 177, 34-41. [CrossRef]

8. Hagen, K.; Broom, D.M. Emotional reactions to learning in cattle. Appl. Anim. Behav. Sci. 2004, 85, 203-213. [CrossRef]

9. McGowan, R.T.; Rehn, T.; Norling, Y.; Keeling, L.J. Positive affect and learning: Exploring the "Eureka Effect" in dogs. Anim. Cogn. 2014, 17, 577-587. [CrossRef]

10. Coleman, K.; Pierre, P.J. Assessing anxiety in nonhuman primates. ILAR J. 2014, 55, 333-346. [CrossRef]

11. Elder, C.M.; Menzel, C.R. Dissociation of cortisol and behavioral indicators of stress in an orangutan (Pongo pygmaeus) during a computerized task. Primates 2001, 42, 345-357. [CrossRef]

12. Leavens, D.A.; Aureli, F.; Hopkins, W.D.; Hyatt, C.W. Effects of cognitive challenge on self-directed behaviors by chimpanzees (Pan troglodytes). Am. J. Primatol. 2001, 55, 1-14. [CrossRef]

13. Yamanashi, Y.; Matsuzawa, T. Emotional consequences when chimpanzees (Pan troglodytes) face challenges: Individual differences in self-directed behaviours during cognitive tasks. Anim. Welf. 2010, 19, 25-30.

14. Mendl, M.; Burman, O.H.; Paul, E.S. An integrative and functional framework for the study of animal emotion and mood. Proc. R. Soc. B Biol. Sci. 2010, 277, 2895-2904. [CrossRef]

15. Paul, E.S.; Sher, S.; Tamietto, M.; Winkielman, P.; Mendl, M.T. Towards a comparative science of emotion: Affect and consciousness in humans and animals. Neurosci. Biobehav. Rev. 2020, 108, 749-770. [CrossRef] [PubMed]

16. Clark, F.E. Marine mammal cognition and captive care: A proposal for cognitive enrichment in zoos and aquariums. J. Zoo Aquar Res. 2013, 1, 1-6.

17. Piscitelli, M.A.; Raverty, S.A.; Lillie, M.A.; Shadwick, R.E. A review of cetacean lung morphology and mechanics. J. Morphol. 2013, 274, 1425-1440. [CrossRef]

18. Moreno, K.; Macgregor, R. Bubble trails, bursts, rings, and more: A review of multiple bubble types produced by cetaceans. Anim. Behav. Cogn. 2019, 6, 105-126. [CrossRef]

19. Wiley, D.; Ware, C.; Bocconcelli, A.; Cholewaik, D.; Friedlaender, A.; Thompson, M.; Weinrich, M. Underwater components of humpback whale bubble-net feeding behaviour. Behaviour 2011, 148, 575-602.

20. Pace, D.S. Fluke-made bubble rings as toys in bottlenose dolphin calves (Tursiops truncatus). Aquat. Mamm. 2000, $26,57-64$.

21. Paulos, R.D.; Trone, M.; Kuczaj, S.A., II. Play in wild and captive cetaceans. Int. J. Comp. Psychol. 2010, 23, 701-722.

22. Dudzinski, K.M. Contact behavior and signal exchange in Atlantic spotted dolphins (Stenella frontalis). Aquat. Mamm. 1998, 24, 129-142.

23. Hill, H.M.; Kahn, M.S.; Brilliott, L.J.; Roberts, B.M.; Gutierrez, C.; Artz, S. Beluga (Delphinapterus leucas) Bubble bursts: Surprise, protection, or play? Int. J. Comp. Psychol. 2011, 24, 235-243.

24. Pryor, K.W. Non-acoustic communication in small cetaceans: Glance, touch, position, gesture, and bubbles. In Sensory Abilities of Cetaceans; Thomas, J.A., Kastelein, R.A., Eds.; Springer: Boston, MA, USA, 1990; pp. 537-544.

25. Delfour, F.; Marten, K. Mirror image processing in three marine mammal species: Killer whales (Orcinus orca), false killer whales (Pseudorca crassidens) and California sea lions (Zalophus californianus). Behav. Process. 2001, 53, 181-190. [CrossRef]

26. Moreno, K. Cetacean Exhalation: An Examination of Bottlenose Dolphin (Tursiops Truncatus) Use of Three Bubble Production Types through Associated Behaviors. Ph.D. Thesis, University of Southern Mississippi, Hattiesburg, MS, USA, 2017.

27. Clark, F.E.; Davies, S.L.; Madigan, A.W.; Warner, A.J.; Kuczaj, S.A. Cognitive enrichment for bottlenose dolphins (Tursiops truncatus): Evaluation of a novel underwater maze device. Zoo Biol. 2013, 32, 608-619. [CrossRef] [PubMed]

28. Bateson, M.; Martin, P. Measuring Behaviour: An Introductory Guide; Cambridge University Press: Cambridge, UK, 2021.

29. Holobinko, A.; Waring, G.H. Conflict and reconciliation behavior trends of the bottlenose dolphin (Tursiops truncatus). Zoo Biol. 2010, 29, 567-585. [CrossRef] [PubMed]

30. Magnusson, M.S.; Burgoon, J.K.; Casarrubea, M. Discovering Hidden Temporal Patterns in Behavior and Interaction; Springer: New York, NY, USA, 2016.

31. Magnusson, M.S. T-pattern detection and analysis (TPA) with THEME ${ }^{\mathrm{TM}}$ : A mixed methods approach. Front. Psychol. 2020, 10, 2663. [CrossRef]

32. Fish, F.E.; Hui, C.A. Dolphin swimming-A review. Mammal Rev. 1991, 21, 181-195. [CrossRef]

33. Videler, J.; Kamermans, P. Differences between upstroke and downstroke in swimming dolphins. J. Exp. Biol. 1985, 119, 265-274. [CrossRef] [PubMed]

34. Serres, A.; Delfour, F. Social behaviors modulate bottlenose dolphins (Tursiops truncatus) breathing rate. Anim. Behav. Cogn. 2019, 6, 127-140. [CrossRef]

35. Kuczaj, S.; Lacinak, T.; Fad, O.; Trone, M.; Solangi, M.; Ramos, J. Keeping environmental enrichment enriching. Int. J. Comp. Psychol. 2002, 15, 127-137.

36. Ellsworth, P.C. Appraisal theory: Old and new questions. Emot. Rev. 2013, 5, 125-131. [CrossRef]

37. Moors, A.; Ellsworth, P.C.; Scherer, K.R.; Frijda, N.H. Appraisal theories of emotion: State of the art and future development. Emot. Rev. 2013, 5, 119-124. [CrossRef]

38. McCowan, B.; Marino, L.; Vance, E.; Walke, L.; Reiss, D. Bubble ring play of bottlenose dolphins (Tursiops truncatus): Implications for cognition. J. Comp. Psychol. 2000, 114, 98-106. [CrossRef]

39. Lilley, M.K.; de Vere, A.J.; Yeater, D.B.; Kuczaj, S.A., II. Characterizing curiosity-related behavior in bottlenose (Tursiops truncatus) and rough-toothed (Steno bredanensis) dolphins. Int. J. Comp. Psychol. 2018, 31, 1-22. [CrossRef] 
40. Dudzinski, K.M. Communication and Behavior in the Atlantic Spotted Dolphins (Stenella frontalis): Relationship between Vocal and Behavioral Activities. Ph.D. Thesis, Texas A\&M University, College Station, TX, USA, 1996.

41. Shane, S.H. Behavior and ecology of the bottlenose dolphin at Sanibel Island, Florida. In The Bottlenose Dolphin; Leatherwood, S., Reeves, R.R., Eds.; Academic Press: San Diego, CA, USA, 1990; pp. 245-265.

42. Herzing, D.L. Vocalizations and associated underwater behavior of free-ranging Atlantic spotted dolphins, Stenella frontalis and bottlenose dolphins, Tursiops truncatus. Aquat. Mamm. 1996, 22, 61-79.

43. Bowles, A.E.; Anderson, R.C. Behavioral responses and habituation of pinnipeds and small cetaceans to novel objects and simulated fishing gear with and without a pinger. Aquat. Mamm. 2012, 38, 161. [CrossRef]

44. Ridgway, S.; Dibble, D.S.; Van Alstyne, K.; Price, D. On doing two things at once: Dolphin brain and nose coordinate sonar clicks, buzzes and emotional squeals with social sounds during fish capture. J. Exp. Biol. 2015, 218, 3987-3995. [CrossRef] [PubMed]

45. Dibble, D.S.; Van Alstyne, K.R.; Ridgway, S. Dolphins signal success by producing a victory squeal. International. J. Comp. Psychol. 2016, 29. [CrossRef]

46. King, S.L.; Guarino, E.; Donegan, K.; McMullen, C.; Jaakkola, K. Evidence that bottlenose dolphins can communicate with vocal signals to solve a cooperative task. R. Soc. Open Sci. 2021, 8, 202073. [CrossRef]

47. Kuczaj, S.A.; Winship, K.A.; Eskelinen, H.C. Can bottlenose dolphins (Tursiops truncatus) cooperate when solving a novel task? Anim. Cogn. 2015, 18, 543-550. [CrossRef]

48. Matrai, E.; Kwok, S.T.; Boos, M.; Pogány, Á. Cognitive enrichment device provides evidence for intersexual differences in collaborative actions in Indo-Pacific bottlenose dolphins (Tursiops aduncus). Anim. Cogn. 2021, 1-11. [CrossRef]

49. Jaakkola, K.; Guarino, E.; Donegan, K.; King, S.L. Bottlenose dolphins can understand their partner's role in a cooperative task. Proc. R. Soc. B Biol. Sci. 2018, 285, 20180948. [CrossRef] [PubMed]

50. Clark, F.E. Space to choose: Network analysis of social preferences in a captive chimpanzee community, and implications for management. Am. J. Primatol. 2011, 73, 748-757. [CrossRef] [PubMed]

51. Wood, F.G. Underwater Sound Production and Concurrent Behavior of Captive Porpoises, Tursiops truncatus and Stenella plagiodon. Bull. Mar. Sci. Gulf Caribb. 1953, 3, 120-133.

52. Van der Woude, S.E. Bottlenose dolphins (Tursiops truncatus) moan as low in frequency as baleen whales. J. Acoust. Soc. Am. 2009, 126, 1552. [CrossRef]

53. Boissy, A.; Manteuffel, G.; Jensen, M.B.; Moe, R.O.; Spruijt, B.; Keeling, L.; Winckler, C.; Forkman, B.; Dimitrov, I.; Langbein, J.; et al. Assessment of positive emotions in animals to improve their welfare. Physiol. Behav. 2007, 92, 375-397. [CrossRef] [PubMed] 